lock-down) can potentially negatively impact the psychological well-being of school-age children. In the event of similar future pandemics, strategies need to be in place to safeguard the psychological well-being of individuals by offering them timely and appropriate psychological support, as well as taking the appropriate steps in the effective management of those already affected psychologically.

\section{QUICK, STAB ME IN THE THIGH! OOPS I'VE FORGOTTEN MY EPIPEN-A PEER PILOT SURVEY OF TEENAGERS' PERSPECTIVES}

Katy Tuthill, David Tuthill. UK

\subsection{6/bmjpo-2021-RCPCH.3}

Background Anaphylaxis is a severe life-threatening allergic reaction; the treatment of choice is adrenaline(epinephrine). The most common UK adrenaline auto-injector is the EpiPen. Primary school children (under 11 years) will have this administered by a parent/carer or teacher if in school. Secondary school aged children (11-18) are supposed to carry their EpiPens themselves for self-administration, however many do not. Objectives Pilot survey exploring the reasons that secondary school aged children do not carry their EpiPens and rating suggestions for how to improve this.

Methods A questionnaire was devised exploring these issues asking:

1. Do they have an EpiPen?

2. Their knowledge of EpiPens? (sliding bar range: 0 bad to 10 good)

3. Were they concerned about adolescents not carrying their EpiPens?

4. Which of the following did they think were factors for teenagers not carrying their EpiPens? (Multiple responses accepted).

- Nowhere to put them

- Forgotten

- Expired

- Don't expect them to be needed

- Don't realise they have to

- Other (asked to specify)

5. Rate the following in effectiveness to increase teenagers carrying EpiPens; Smaller Pens; Better education; Better ways to carry them(Likert scale: 1 not good to 5 ideal).

The questionnaire was approved by the school as part of a sixth form Welsh Baccalaureate project. It was sent digitally as a convenience sample to members of the sixth form, Girl Guides and an adult from each family to complete via SurveyMonkey ${ }^{\circledR}$. Comparative statistical tests comparing adults and teenagers results were performed $(\mathrm{p}<0.05$ taken as significant).

Results The survey was sent to 82 teenagers; there were 61 respondents, 35 teenagers and 26 adults.

Q1) Only 2 children had EpiPens.

Q2) EpiPen knowledge: Overall mean score4.4 (SD 2.8). Teenagers mean 4.0 (SD 2.5): adults mean 5.0 (SD 3.1): students t-test $t$-value $1.43 p=0.079$.

Q3) Concerned about EpiPen carriage: Overall yes 47 (77.1\%), no 3(4.9\%), don't know 11(18.0\%). Teenagers yes $30(85.7 \%)$, no $1(2.9 \%)$, don't know 4(11.4\%): adults yes 17 (65.4\%), no 2(7.7\%), don't know 7(26.9\%). Chi-square1.1132 $p=0.29$.
Q4)

\begin{tabular}{lc}
\hline Factors for teenagers not carrying their EpiPens & $\mathbf{n}(\%)$ \\
\hline Nowhere to put them & $27(44 \%)$ \\
Forgotten & $37(61 \%)$ \\
Expired & $7(11 \%)$ \\
Not expected to be needed & $45(74 \%)$ \\
Don't realise they have to & $17(28 \%)$ \\
Other & $9(15 \%)$ \\
\hline
\end{tabular}

Q5)

\begin{tabular}{|c|c|c|c|c|c|}
\hline \multirow{2}{*}{$\begin{array}{l}\text { Methods to improve } \\
\text { carriage }\end{array}$} & \multicolumn{3}{|c|}{ Mean rating(1-5) } & \multirow{2}{*}{$\begin{array}{l}\text { Mann- } \\
\text {-Whitney } \\
\text { U value }\end{array}$} & \multirow[t]{2}{*}{$P$ value } \\
\hline & $\begin{array}{l}\text { Overall } \\
\text { score }\end{array}$ & Adults & Teenagers & & \\
\hline Smaller Pens & 3.5 & 3.6 & 3.5 & 418.5 & 0.84 \\
\hline Better education & 4.1 & 3.9 & 4.3 & 359.0 & 0.24 \\
\hline Better ways to carry them & 3.7 & 3.6 & 3.9 & 376.5 & 0.36 \\
\hline
\end{tabular}

Conclusions There was a wide range of self-reported knowledge scores about EpiPens and most respondents were concerned that EpiPens were often not carried. They felt the reasons for this included; not expecting them to be needed, forgetting them and not having anywhere to carry them due to their size. Almost all respondents felt that education and an improved, smaller design for both EpiPens and their carrycases would increase carriage rates. In this pilot survey no differences between adults and children were demonstrated.

Sixth form student projects may enable teenagers' perspectives on medical topics to be assessed through a non-threatening peer evaluation. Post-Covid this peer based digital technique may warrant further exploration.

\section{ULTRASOUND GUIDED FLUID RESUSCITATION IN PEDIATRIC SEPTIC SHOCK: A RANDOMIZED CONTROLLED TRIAL}

Ryan Sohail Kaiser, Satyabrata Roychowdhury, Mihir Sarkar, MOUSUMINANDI Ghosh. India

\subsection{6/bmjpo-2021-RCPCH.4}

Background Over-zealous fluid resuscitation in septic shock can lead to fluid overload and its associated poor outcomes. Hence we need dynamic markers of fluid responsiveness to better guide fluid therapy in children with septic shock. Ultrasound parameters are an option available to PICU physicians for the same.

Objectives To evaluate the role of Ultrasound in reducing the incidence of fluid overload in children with septic shock. Fluid overload was defined as Cumulative fluid balance percentage $(\mathrm{CFB} \%)>10 \%$. The primary outcome was a reduction in the number of patients with fluid overload on day 3 of admission. Secondary outcomes were resuscitation and shock reversal time, total fluid bolus, fluid overload on day 1, use of Furosemide and inotropes, the occurrence of AKI, the requirement of mechanical ventilation, length of stay, and mortality.

Methods This is a prospective randomized controlled superiority trial, conducted in the PICU of a government-aided 